\title{
Theory/Analysis Mismatch: Comment on Fredrickson and Joiner's (2002) Test of the Broaden-and-build Theory of Positive Emotions
}

\section{Carol Nickerson}

Published online: 22 August 2007

(C) Springer Science+Business Media B.V. 2007

1 Erratum to: Journal of Happiness Studies (2007) DOI 10.1007/s10902-006-9030-5

Please note that the abstract in the original article was incorrect. The correct abstract should be:

Fredrickson's (1998, 'What good are positive emotions?', Review of General Psychology 2, pp. 300-319; 2001, 'The role of positive emotions in positive psychology: The broaden-and-build theory of positive emotions', American Psychologist 56, pp. 218226) broaden-and-build theory of positive emotions posits that positive emotions improve coping skills and that improved coping skills increase positive emotions, resulting in an upward spiral toward emotional well-being. Fredrickson and Joiner (2002, 'Positive emotions trigger upward spirals toward emotional well-being', Psychological Science 13, pp. 172-175) claimed that the results of their analyses supported the broaden-and-build theory but in fact their analyses did not test this theory. The broaden-and-build theory clearly describes a within-person across-occasions psychological process; the analyses, however, tested a within-occasion across-persons theory.

The online version of the original article can be found under doi:10.1007/s10902-006-9030-5.

C. Nickerson $(\bowtie)$

203 North Lynn Street 35, Champaign, IL 61820, USA

e-mail: cnickers@cyrus.psych.uiuc.edu 